\title{
A governança não estatal da internet e o direito brasileiro ${ }^{1 *}$
}

\section{Internet non-state governance and the Brazilian law}

\author{
Carlos Ari Sundfeld** \\ André Rosilho***
}

\section{RESUMO}

Para o direito brasileiro, o sistema internet (registros de nomes do domínio ".br", distribuição de endereços IP e sua regulação) é um serviço de valor adicionado, não sujeito a regulação pública (Lei no 9.472, de 1997, art. 61).

* Artigo recebido em 4 de julho de 2014 e aprovado em 4 de agosto de 2015. DOI: http://dx.doi. org/10.12660/rda.v270.2015.58737

1 Este artigo é um dos resultados de pesquisa para o Comitê Gestor da Internet no Brasil (CGI. br) e o Núcleo de Informação e Coordenação do Ponto Br (NIC.br). Os autores agradecem as informações e entrevistas de Demi Getschko (presidente do NIC.br), Eduardo Fumes Parajo (conselheiro da CGI.br), Kelli Angelini (assessora jurídica da CGI.br), bem como de Elinor Cotait e Tomás Schoeller Paiva (Mundie Advogados).

** Fundação Getulio Vargas, São Paulo, São Paulo, Brasil. E-mail: carlos@sundfeld.adv.br.

Professor Fundador da Escola de Direito de São Paulo da Fundação Getulio Vargas e presidente da Sociedade Brasileira de Direito Público (SBDP). Doutor e mestre pela Faculdade de Direito da PUC/SP.

*** Universidade de São Paulo, São Paulo, São Paulo, Brasil. E-mail: andre@sundfeld.adv.br.

Mestre pela Escola de Direito de São Paulo da Fundação Getulio Vargas. Doutorando pela Faculdade de Direito da USP. Coordenador do Curso de Direito Público da Sociedade Brasileira de Direito Público (SBDP). 
As organizações que o gerem (CGI.br e NIC.br) têm a participação do Estado brasileiro (Decreto Federal no 4.829 , de 2003), mas não são agentes dele, e sim de um sistema global coordenado pela Icann.

\section{PALAVRAS-CHAVE}

Internet - serviço de valor adicionado - Icann - CGI.br e NIC.br Lei no 9.472, de 1997, art. 61 - Decreto Federal no 4.829, de 2003

\section{ABSTRACT}

To the Brazilian law, the Internet system (domain name registrations ".br", distribution of IP addresses and their regulation) is not subject to public regulation (Law 9472 of 1997, art. 61). According to the federal decree 4829, 2003, the Brazilian state is part of the organizations that manage it (CGI. br and NIC.br), but do not control them. The institutions are coordinated by Icann.

\section{KEYWORDS}

Internet - non-public service - Icann - CGI.br and NIC.br - Law 9.472, 1997, art. 61 - Federal Decree 4.829, 2003

\section{Sistema internet, estados nacionais e direito global}

O funcionamento da internet é decorrência do sistema tecnológico que correlaciona um conjunto de códigos, os nomes de domínio, com os endereços internet - "IPs", viabilizando a comunicação entre eles, por transmissão de dados. Como toda política pública, a que assegura a existência da internet em escala mundial também é construída por normas que desenham arranjos institucionais, criam procedimentos, fixam objetivos e convocam atores para concretizá-los, conferindo-lhes plexos de atribuições específicas. ${ }^{2}$ A despeito de apresentar características do gênero ao qual pertence, a política do

2 O sistema internet não é o responsável por regular o conteúdo veiculado na rede mundial de computadores; seu papel é apenas o de viabilizar o funcionamento dessa rede, não o de dispor sobre as informações que por meio dela são trocadas. Estão afastadas do presente estudo, assim, preocupações ligadas, por exemplo, ao debate, relacionado ao Marco Civil da Internet (Lei no 12.965, de 23 de abril de 2014), quanto à possibilidade de retirada de conteúdo da rede. 
sistema internet possui ao menos uma particularidade: diferentemente das mais comuns, erigidas por normas estatais nacionais para o cumprimento de objetivos previamente definidos por um Estado nacional (em geral a consecução de empreendimentos nacionais), a política de interesse público da internet tem por meta realizar empreendimento essencialmente global. Essa peculiaridade faz diferença.

O sistema internet não se confunde com o sistema de telecomunicações. Ao traçar suas definições, a Lei Geral de Telecomunicações (Lei no 9.472, de 16 de julho de 1997) distinguiu o sistema de telecomunicações ("conjunto de equipamentos ou aparelhos, dispositivos e demais meios necessários à realização de telecomunicação", art. $60, \S \S 1^{\circ}$ e $2^{\circ}$ ) do serviço de valor adicionado ("atividade que acrescenta, a um serviço de telecomunicações que lhe dá suporte e com o qual não se confunde, novas utilidades relacionadas ao acesso, armazenamento, apresentação, movimentação ou recuperação de informações", art. 61, caput). A internet e seu sistema estão inseridos nesta última categoria - a dos serviços de valor adicionados - , já que dependem da infraestrutura de telecomunicações para operar, mas com ela não se confundem.

A lei, ao criar estas duas figuras - telecomunicações e valor adicionado -, diferenciou, por um lado, a estrutura física e lógica criada para a conexão primária de pessoas e lugares, e, por outro, as estruturas posteriores, físicas ou lógicas, que venham a ser sobrepostas à primeira, para acrescentar-lhe novas utilidades, viabilizando, por exemplo, um novo modo de troca de informações.

Os serviços de telecomunicações e de valor adicionado têm regimes jurídicos diferentes. Enquanto os primeiros incluem-se entre os serviços de titularidade estatal (Constituição Federal, art. 21, XI) e só podem ser prestados por outorga estatal, feita por concessão ou autorização, e por prestadores sujeitos à regulação estatal, a cargo da Agência Nacional de Telecomunicações (Anatel), os serviços de valor adicionado são livres e, por não dependerem de qualquer outorga estatal, estão isentos da regulação pública vinculada a esse tipo de outorga (Lei no 9.472, de 1997, art. 61, §§). ${ }^{3}$

A figura do serviço de valor adicionado não é especificidade brasileira. Ela foi adotada ou aceita de modo generalizado pelos direitos dos distintos

3 SUNDFELD, Carlos Ari. Regime do serviço de valor adicionado a telecomunicações. In: Pareceres, v. I - Direito administrativo econômico. São Paulo: Thomson Reuters; Revista dos Tribunais, 2013. p. 379-388. 
países, e se tornaria fundamental a partir dos anos 1990, exatamente para evitar que os avanços tecnológicos em telecomunicações e informática, que então ocorriam, acabassem ficando com seu uso limitado e condicionado pelos monopólios estatais existentes historicamente no setor de telecomunicações. ${ }^{4}$ A liberdade, expressa na figura do serviço de valor adicionado, foi considerada o princípio básico dessa nova era de atividades viabilizadas pela tecnologia nascente no final do século XX, ao contrário do que ocorrera um século antes com as telecomunicações. $\mathrm{O}$ sistema internet desenvolveu-se como atividade livre justamente nesse novo ambiente.

A política de interesse público, no caso do sistema internet, não é produto direto de Estados nacionais - tampouco está relacionada a funções que lhes sejam próprias ou responde, de forma imediata, a interesses, preocupações ou necessidades especificamente estatais..$^{5}$ É uma política que, conquanto de objetivos públicos, não é estatal. Ela é produzida por atores distintos dos Estados nacionais e destina-se a empreendimento essencialmente transnacional, coletivo - e também não estatal. Seu DNA, portanto, é global - e não nacional, como o das políticas públicas estatais tradicionais.

Certos arranjos de abrangência global, conquanto não pudessem surgir da ação isolada de Estados nacionais - pela evidente incapacidade de cada um deles criar por si algo que extrapolasse sua esfera de influência territorial -, foram viabilizados e se mantêm justamente pela união de Estados nacionais. Os serviços de telecomunicações - que, em seus primórdios, na forma de telegrafia ou telefonia, eram apenas locais - foram aos poucos se conectando em escala mundial e hoje, sem deixarem de ser nacionais, isto é, outorgados e regulados pelos Estados nacionais, funcionam de modo integrado em todo o mundo.

Como isso se viabilizou? Por meio dos sucessivos acordos entre os Estados nacionais. O primeiro acordo bilateral surgiu em 1849. O primeiro acordo multilateral é de 1865, dele resultando a criação de uma organização intergovernamental ainda existente, hoje com o nome de União Internacional de Telecomunicações (UTI), e que congrega a generalidade dos países. A UIT,

4 RAVENTÓS, Alberto. Servicios de valor añadido: conmutación de datos por paquetes, por circuitos... In: CREMADES, Javier (Coord.). Derecho de las telecomunicaciones. Madri: La Ley, 1997. p. 377-400.

5 Para uma análise da relação entre direito e políticas públicas especificamente estatais (e das sinergias que entre eles existem), v. SUNDFELD, Carlos Ari; ROSILHO, André. Direito e políticas públicas: dois mundos? In: Paulo: Malheiros, 2014. p. 45-79. 
juntamente com outra organização intergovernamental, a Organização das Nações Unidas (ONU), é quem exerce função regulatória internacional nessa matéria.

Nesse modelo das telecomunicações, baseado em organizações intergovernamentais, os Estados nacionais conservam de certo modo o protagonismo do domínio internacional, de maneira que as soluções globais são, imediata ou mediatamente, composições de interesses realizadas entre Estados soberanos, segundo as regras institucionais que eles mesmos estabeleceram. Assim, as principais soluções globais em matéria de telecomunicações se expressam em um direito internacional público das telecomunicações, criado ao longo de uma história de mais de 160 anos. $^{6}$

As coisas se passaram diferentemente no campo dos serviços de radiodifusão, apesar de, no âmbito de cada país, esses serviços dependerem sempre de outorga estatal e se sujeitarem, portanto, à regulação estatal. $\mathrm{O}$ fato é que, ao contrário do que ocorreu nas telecomunicações, os Estados nacionais não se dedicaram à construção de um amplo direito internacional público específico da radiodifusão. Como, todavia, para certos efeitos - por exemplo, para a segurança jurídica quanto à titularidade e ao licenciamento do uso de programação televisiva - mostrava-se necessária ou útil a adoção de certos padrões internacionais, foram surgindo várias organizações internacionais não governamentais, de âmbito regional, que se incumbiram de desenvolver as soluções jurídicas correspondentes.

Essas soluções podem ser consideradas integrantes de um direito internacional privado da radiodifusão, no sentido de um direito cuja origem nem está nas normas de Estados nacionais nem está na ação de organizações intergovernamentais de âmbito internacional. ${ }^{7}$ Apesar disso, trata-se de um direito internacional privado de interesse público, destinado a introduzir políticas que realizem objetivos coletivos permanentes. Daí, inclusive, a necessidade de existirem organizações internacionais (não governamentais, nesse caso), para gerar e cuidar desse conjunto jurídico.

Ao contrário das telecomunicações e da radiodifusão, que surgiram como empreendimentos locais monopolizados ou regulados pelos Estados nacionais, o sistema internet não só foi desenvolvido no ambiente da livreiniciativa, como já havia sido originalmente concebido para ser global, isto

\footnotetext{
TCHIKAYA, Blaise. Le droit international des télécommunications. Paris: PUF, 1998.

FERNÁNDEZ-SHAW, Félix. Organización internacional de las telecomunicaciones y de la radiodifusión. Madri: Tecnos, 1978. p. 221 e ss.
} 
é, para superar os limites dos Estados nacionais. Assim, o direito global do sistema internet não tinha como nascer da união de Estados nacionais, tendo sido natural que adotasse a forma de um direito global não estatal (que não veio de organizações intergovernamentais). Mas nem por isso suas características são as de um conjunto normativo destinado a realizar os interesses especificamente privados dos sujeitos que criaram o sistema internet. A estrutura de governança que se construiu propiciou, para o sistema internet, um direito global de interesse público, embora não estatal.

O caráter híbrido da política de interesse público do sistema internet - materializado principalmente no fato de ela não ter origem estatal, mas conter notas que também aparecem nos direitos administrativos dos Estados nacionais (já que pretende regular e disciplinar comportamentos em vista de certas finalidades coletivas) - tem levado alguns estudiosos do direito a afirmar que este seria um dos exemplos mais notórios da emergência do que convencionaram chamar de direito administrativo global, um direito não necessariamente ligado aos Estados, mas voltado sim à promoção de interesses gerais e de valores públicos. ${ }^{8}$

O desafio colocado pela internet é interessante: seu sistema de fato é um empreendimento marcadamente global, indiferente à geografia e aos Estados, mas as organizações responsáveis por seu funcionamento, mesmo envolvidas em empreendimentos transnacionais, precisam estar situadas em algum território; elas têm de existir nalgum espaço físico, isto é, nalgum país e segundo algum sistema jurídico nacional. Essas organizações estão espalhadas pelos mais diversos países do mundo, atuando em conjunto e em harmonia para organizar, gerir e manter o sistema internet. A empreitada consiste num esforço de cooperação, que se desenrola nos níveis global, regional e local.

Por estarem sediadas em muitos Estados nacionais diferentes, as organizações acabaram assumindo formas e contornos variados, de modo a se ajustarem às suas particularidades; não houve um padrão. Em alguns casos,

8 Neste sentido, KINGSBURY, Benedict; KRISCH, Nico; STEWART, Richard B. The emergence of global administrative law. Disponível para consulta no sítio eletrônico do Global Administrative Law Project da New York University School of Law (<www.iilj.org/gal/>). V. também, NASSER, Salem H. O direito global em pedaços - regimes, fragmentação e pluralismo. V. 1 de texto apresentado à Escola de Direito de São Paulo da Fundação Getulio Vargas (FGV Direito SP) para fins de progressão na carreira de docente da instituição (2012); CHITI, Edoardo; MATTARELLA, Bernardo Giorgio (Org.). Global administrative law and EU administrative law: relationships, legal issues and comparison. Berlim: Springer, 2011; e CASINI, Lorenzo. Além do Estado: o surgimento da administração global. Revista de Direito Administrativo, Rio de Janeiro, v. 267, p. 13-40, set./dez. 2014. 
a governança local do sistema internet foi incorporada por universidades; noutros, por outras instituições não estatais ou por entidades estatais. Tiveram, assim, que encontrar um equilíbrio tênue: precisaram, a um só tempo, se ajustar aos contextos locais - político, econômico, geográfico, cultural, social, jurídico etc. - e localmente viabilizar o sistema internet.

No Brasil, o sistema é gerido por duas organizações peculiares, que atuam em conjunto e em sintonia: o CGI.br e o NIC.br. Elas são responsáveis por coordenar e atribuir endereços IP em território nacional e por coordenar e registrar nomes de domínio usando o ".br".

O CGI.br, organização sem personalidade jurídica, tem previsão no Decreto Federal no 4.829, de 3 de setembro de 2003. ${ }^{9}$ A despeito de ter oficialmente surgido no decreto, não integra a administração pública federal. Dele fazem parte membros do governo (em número relevante, porém minoritário), representantes do setor empresarial, do setor acadêmico, do terceiro setor e da comunidade científica e tecnológica. O NIC.br, por sua vez, é pessoa jurídica de direito privado, também não estatal, instituída na modalidade associação, sem fins lucrativos, incumbida de implementar decisões e projetos do CGI.br. É, assim, seu braço executor.

Por se tratar de modelo de governança inovador - inclusive pelo prisma jurídico - , é natural que surjam dúvidas ligadas às suas características e à sua organização. ${ }^{10}$ Além disso, no ambiente acadêmico há questionamentos sobre a legalidade desse arranjo jurídico e sobre a legitimidade do CGI.br e do NIC. br para gerenciar números IP e o registro de nomes de domínio sob o “.br". ${ }^{11}$

9 Esse decreto substituiu a Portaria Interministerial no 147, de 31 de maio de 1995.

10 Ilustrativo é o ajuizamento de ações por particulares contra o NIC.br $e$ a União Federal em decorrência de negativa do pedido de registro de nome de domínio (que ocorre, p.ex., quando se pede o registro, sob o ".br", de marcas conhecidas e valiosas, como "coca-cola" ou "marlboro", numa tentativa de auferir vantagens indevidas). Para cogitar do interesse da União nessas causas, os autores levaram em consideração o fato de o NIC.br ser braço executor do CGI.br e de este comitê ter sido previsto em decreto presidencial, talvez entendendo-a como pertencente à administração pública. Mas, nessas circunstâncias, a Justiça Federal, em solução correta, tem normalmente excluído a União do polo passivo e declinado da competência para julgar. Exemplos: Agravo de Instrumento no0 0012297-54-2012.4.01.0000/MG, Tribunal Regional Federal da Primeira Região, desembargadora Selene Maria de Almeida; Ação Ordinária no 4108-72.2012.4.01.3400/DF, Justiça Federal do Distrito Federal, juiz Ivani Silva da Luz; Ação Ordinária no 0018047-89.2007.4.03.6100/SP, 12ª Vara da Justiça Federal de São Paulo; e Ação Ordinária no 11465-67.2012.4.01.3800/MG, Justiça Federal de Minas Gerais, juíza Gabriela de Alvarenga Silva Murta.

11 O artigo "Os novos mercados de nomes e números da internet - reestruturação do sistema de governança brasileiro", de Andrey Vilas Boas de Freitas e Igor Vilas Boas de Freitas, relaciona algumas dúvidas quanto ao modelo de governança do sistema internet no Brasil (Núcleo de Estudos e Pesquisas/Conleg/Senado, Brasília, 2013 - texto para discussão no 139. Disponível em: <www.senado.leg.br/estudos>). 
O objetivo do presente estudo é refletir sobre essas dúvidas e questionamentos.

\section{Desenvolvimento do sistema internet}

A ramificação do sistema internet no Brasil seguiu trajetória interessante e desenvolveu uma governança inovadora - inclusive para os padrões internacionais. Nosso modelo - cujos principais atores, como dito, hoje são o CGI.br e o NIC.br - de algum modo procura mimetizar o espírito essencialmente plural, coletivo, do próprio sistema internet. Não é puramente estatal, tampouco é privado (no sentido de vinculado à realização de interesses particulares específicos); é pluralista, coletivo, conduzido pelo consenso das vozes representativas da coletividade. Trata-se de modelo não estatal de corregulação pluriparticipativo e consensual. Algumas das vozes representadas nesse modelo são de diferentes órgãos ou entidades do Estado brasileiro.

A formalização do CGI.br por decreto não objetivou torná-lo estatal. Essa foi a mera forma de o Estado aderir ao modelo, então já existente, de governança local do sistema internet, que opera em escala global, emprestando-lhe apoio e legitimidade. Noutras palavras, foi o veículo por meio do qual o Estado formalizou sua participação em modelo no qual reconheceu alto valor.

O caráter não estatal da estrutura de governança do sistema internet no Brasil - modelo esse que, por meio do citado decreto, recebeu o reconhecimento e a adesão da administração pública federal - é coerente com a opção legal brasileira, resultante do art. 61 da Lei Geral de Telecomunicações, de reconhecer ampla liberdade para a organização de serviços de valor adicionado a telecomunicações. Os serviços de valor adicionado não são organizados por ação prestacional ou regulatória do Estado brasileiro; são organizados livremente, pela iniciativa dos sujeitos que os criarem e lograrem manter.

O sistema internet, estruturado dessa forma em escala mundial, funciona assim também no Brasil, e isso porque a lei brasileira o quis expressamente. Esse sistema, desenvolvido no ambiente da livre-iniciativa, foi bem-sucedido, atendendo igualmente a usuários estatais e não estatais, pessoas físicas e jurídicas. Era natural que o Estado brasileiro, que já assegurara por lei a liberdade que deu espaço para esse empreendimento também no Brasil, viesse então a emprestar seu reconhecimento e apoio ao empreendimento que se firmara, naturalmente sem mudar com isso sua característica não estatal. 


\subsection{Origem do sistema internet}

A internet, em seu formato atual, poderia ser definida como rede global de redes interconectadas, nas quais ocorrem trocas de "pacotes" de dados por meio do protocolo TCP/IP (Transmission Control Protocol/Internet Protocol). ${ }^{12}$ Sua origem está em um projeto de pesquisa sobre conexão de computadores em rede, iniciado nos anos 1960, nos Estados Unidos da América (EUA), e financiado pelo United States Advanced Research Project Agency (Arpa). A pesquisa inicialmente resultou numa rede experimental, estabelecida em 1969, conhecida como Arpanet.

A grande inovação do experimento foi a criação do conceito de "troca de pacotes" (packet-switching), consistente, em síntese, na divisão de mensagens em pequenas unidades digitais, conhecidas como "pacotes" (packets), e na sua transmissão, por rotas e caminhos diversos, até sua destinação final. Outro importante elemento da pesquisa Arpanet envolveu o desenvolvimento de protocolos de rede - os protocolos estabelecem regras que disciplinam a comunicação entre computadores; os primeiros foram desenvolvidos por um grupo de estudantes de pós-graduação da University of California, Los Angeles (Ucla).

$\mathrm{O}$ protocolo que posteriormente viria a se tornar padrão mundial, o TCP/IP, consubstanciou-se em um importante avanço, aprimorando a confiabilidade da comunicação entre redes. Esse padrão funciona com base em lógica interessante. O protocolo TCP responsabiliza-se pela divisão das mensagens em "pacotes" e por colocar os fragmentos de mensagens em envelopes eletrônicos (a eles anexando cabeçalhos), remontar os "pacotes" na destinação final, corrigir erros e retransmitir os "pacotes" em caso de falhas de

12 Essa definição encontra eco, por exemplo, em resolução do Federal Networking Council, corpo responsável por coordenar redes de comunicação entre agências federais dos EUA, aprovada em 24 de outubro de 1995. Confira-se o texto da resolução: “O Federal Networking Council (FNC) concorda que a seguinte linguagem reflete nossa definição do termo 'Internet': 'Internet' refere-se ao sistema de informação global que - (i) está logicamente ligado por um espaço de endereço único e global no Protocolo de Internet (IP) ou por suas subsequentes extensões/follow-ons. (ii) é capaz de apoiar comunicações por meio do Protocolo Controle de Transmissão/Protocolo Internet (TCP/IP) ou suas subsequentes extensões/follow-ons, e/ ou outro protocolo compatível com IP; e (iii) providencie, use ou torne acessível, pública ou privadamente, serviços em camada de alto nível sobre comunicações e infraestrutura relacionadas aqui descritas"' (tradução livre). Para o texto da resolução e outras informações, que estão sintetizadas abaixo, v. LINDSAY, David. International domain name law - Icann and the UDRP. Portland: Hart Publishing, 2007. p. 1. 
transmissão; o protocolo IP, por sua vez, é o responsável por passar "pacotes" de uma rede para outra.

Esse mecanismo facilita e simplifica a transmissão de dados, já que o fato de as mensagens serem fragmentadas e encapsuladas em envelopes eletrônicos com cabeçalhos comuns faz com que os computadores transmissores (routers) não precisem se preocupar com o conteúdo das mensagens, mas apenas com o seu envelope e com as informações do remetente e do destinatário constantes do cabeçalho.

Em linhas muito gerais, esta é a tecnologia que está na base do sistema internet. Para que ela efetivamente viabilizasse a comunicação online, no entanto, foi preciso avançar para o desenvolvimento de uma linguagem virtual específica, que pudesse ser assimilada tanto por computadores quanto por seres humanos. A solução materializou-se na criação do Sistema de Nomes de Domínio (Domain Name System - DNS).

\subsection{Linguagem da internet}

O sistema internet se baseia em um mecanismo de endereçamento que combina nomes e endereços numéricos. Os nomes funcionam como identificadores simples - referindo-se, por exemplo, a pessoas ou computadores específicos -, enquanto os endereços numéricos, para além de cumprirem função similar à dos nomes, também revelam a localização física ou lógica dos computadores ou organizações em geral.

A decisão de atribuir nomes aos endereços numéricos de cada um dos servidores (computer host), combinando-os, foi tomada logo no início do sistema e foi motivada por duas razões principais. De um lado, porque nomes são mais fáceis de serem memorizados e manuseados por seres humanos do que longas sequências numéricas. De outro, porque nomes são mais estáveis do que endereços numéricos, os quais, com o tempo, estão sujeitos, por exemplo, a ampliações ou a redesignações.

Os endereços numéricos (ou endereços IPs), para serem criados, precisaram ter seus espaços definidos. Atualmente, dois são os espaços de IP existentes: os chamados IPv4 e IPv6 (este muito maior do que aquele). Os números de IP - extraídos do IPv4 ou do IPv6, tanto faz - , para possibilitarem a transmissão de mensagens por redes de computadores, obrigatoriamente devem ser únicos, inconfundíveis. Do contrário, não seria possível aferir com precisão e certeza a localização lógica dos computadores destinatários. 
Os nomes atribuídos aos números de IP são chamados de nomes de domínio (domain name). O uso de nomes para facilitar o manuseio da internet por seres humanos pôs uma dificuldade técnica ao funcionamento da internet: como os computadores, que são aptos a ler números, mas não nomes, fariam a correlação entre nomes de domínio e números IP? A resposta a essa indagação foi dada por meio da criação do Sistema de Nomes de Domínio (Domain Name System - DNS), cuja principal função é justamente ligar nomes a endereços IP. ${ }^{13}$

A estratégia do DNS para fazer essa conexão consistiu na criação de um ambiente hierarquicamente organizado, contendo, no topo, uma raiz e, abaixo dela, uma estrutura em árvore. A raiz não recebeu nome algum é representada por um único ponto ("."). A figura do ponto (".") também é utilizada para separar as conexões entre os níveis hierárquicos dentro do espaço de nomes de domínio. Abaixo da raiz encontram-se subárvores e ramos - as subárvores representam domínios diferentes.

Convencionalmente, nomes de domínio são lidos da esquerda para a direita, e o nome mais específico - mais afastado da raiz - fica à esquerda (trata-se do nome do servidor, ou computer host), enquanto o mais geral mais perto da raiz - fica à direita. No exemplo "usp.br", "usp" é o computer host e o nome de domínio mais geral é o ".br".

Subjaz à criação do DNS nesse formato a intenção de permitir a descentralização da administração das funções de nomeação e atribuição de endereços de internet. ${ }^{14} \mathrm{O}$ arranjo hierárquico reflete esse objetivo, concretamente permitindo a delegação da responsabilidade de gerenciar nomes de domínios com hierarquias diferentes a organizações distintas.

Todos os nomes de domínio, sem exceção, obrigatoriamente devem aludir e se conectar a um domínio de primeiro nível (Top-level Domain - TDL), localizado em espaço mais próximo da raiz do sistema. Os TDLs, segundo resolução datada de 1984, se subdividem em duas categorias: os Generic Top-level Domains (gTLDs) e os Country Code Top-level Domains (ccTLDs).

13 Pesquisadores ligados ao Information Sciences Institute (ISI) - instituto fundado em 1972 e afiliado à University of South California - foram os que mais se engajaram em investigações relativas aos conceitos subjacentes ao DNS. As principais figuras do ISI envolvidas na pesquisa foram Steve Crocker, Jon Postel e Paul Mockapetris (David Lindsay, International domain name law - Icann and the UDRP, op. cit., p. 6-7).

14 Confira-se tradução livre da fala de Jon Postel e de Joyce Reynolds a respeito dos objetivos do espaço de nomes de domínio: “Domínios são entidades administrativas. O propósito e uso esperado dos domínios é dividir a gerência de nomes requerida por uma administração central e atribuí-las a subadministrações" (Ibid.). 
Inicialmente, foram fixados apenas cinco gTLDs (".com", ".edu", ".gov", ".mil", ".gov"), os quais, em tese, indicariam o tipo de atividade ou de utilidade a que seriam atrelados. Por exemplo, imaginou-se que o domínio “.com" seria alocado a entidades voltadas a finalidades comerciais, enquanto o domínio ".gov" seria alocado a órgãos ou entidades governamentais.

A ideia de criar os ccTLDs surgiu a partir de uma constatação importante: dada a extensão da colaboração internacional no projeto de desenvolvimento e de pesquisa de redes, o interesse no DNS extrapolaria, e muito, os cientistas localizados nos EUA. Daí o desenvolvimento de uma categoria de TLD não atrelada a funções ou a utilidades, mas a limites geográficos (ou a limites de Estados nacionais).

Para evitar previsíveis controvérsias sobre a designação mais adequada de cada localidade, Postel decidiu calcar os ccTLDs em parâmetro já existente e conhecido, a tabela de abreviações de países ISO-3166, elaborada pela International Standardization Organization (ISO). Pela tabela, territórios geográficos são representados por códigos compostos por duas letras alfabéticas. A região correspondente ao território brasileiro, por exemplo, é representada pelo ".br". ${ }^{15}$

A observação das características gerais do sistema internet demonstra, de maneira inequívoca, que seu funcionamento, para além de obviamente depender da existência de estrutura de telecomunicações e de tecnologia apropriadas, demanda coordenação e gestão centralizadas. A governança vertical do sistema é imprescindível ao desenvolvimento de um ambiente global para troca de informações, pautado por um único padrão tecnológico (por exemplo, o protocolo TCP/IP) e por um único código de linguagem (representado, por exemplo, pelo sistema de nomes de domínio). A ausência de certo grau de uniformização da internet frustraria a possibilidade de comunicação online em escala global.

\subsection{Governança global do sistema internet}

A história da governança do sistema internet é rica e repleta de movimentos, de idas e vindas. Sua estrutura atual é produto de um longo processo

15 Vale frisar que os ccTLDs, apesar do nome, não se referem propriamente a países, mas a regiões. São, isto sim, domínios referentes a um código de país. 
de maturação, sendo praticamente impossível compreendê-la sem retomar suas origens. ${ }^{16}$

Um aspecto manteve-se no tempo. A internet, embora possa ser vista como um serviço, não foi instituída a partir de qualquer monopólio ou "publicatio" desse novo setor, criado por qualquer Estado nacional. O surgimento e o desenvolvimento posterior foram um fato que juridicamente se viabilizou pela boa razão de que as normas de cada país deixavam liberdade para os privados atuarem nesse campo. Valendo-se da liberdade de empreender, particulares montaram e mantêm o sistema, sem exercerem para tanto qualquer tipo de autoridade pública, tampouco se beneficiando de privilégios tipicamente estatais.

O sistema internet, no início, contava com administração bastante informal. Reflexo dessa característica é a centralização da atribuição de decidir em indivíduos específicos, nomeadamente Jon Postel - e seus colegas de trabalho - , tido como o "pai" do sistema de nomes de domínio. O interessante é observar que mesmo nesse ambiente marcado pela informalidade inexistindo instituições propriamente ditas que por ele fossem responsáveis - havia a preocupação de criar padrões de funcionamento para o sistema. ${ }^{17}$

Este modelo informal de governança mostrou-se adequado, ao menos por um período de tempo. Mas sua insuficiência viria a ficar evidente com o agigantamento da internet, dando ensejo à necessidade de ser ajustado para que pudesse gerir um espaço de endereços e de nomes de domínio crescentemente complexo.

Em 1988, o já mencionado Arpa, órgão do governo norte-americano, ao renovar o contrato de pesquisa que mantinha com o Information Science Institute (ISI) - do qual Jon Postel fazia parte - , o fez aceitando que este exercesse funções ligadas à padronização e à organização do sistema internet. Nesse mesmo momento, o ISI foi internamente reorganizado, passando a se chamar Internet Assigned Numbers Authority (Iana).

A Iana informalmente transformou-se na grande gestora do sistema internet, detendo, por exemplo, poderes de fato para designar identificadores numéricos necessários à operação da internet e para delegar, a seu critério, parcela dessa competência a outras organizações.

16 Para informações completas sobre a evolução da governança do sistema internet, consultar, David Lindsay, International domain name law - Icann and the UDRP, op. cit. International domain name law - Icann and the UDRP, op. cit., p. 27-94.

17 A fixação de balizas para o sistema passou a ocorrer por meio das chamadas Request for Comments (RFCs). Cf. Ibid., p. 3. 
Posteriormente, uma série de fatores conduziria à realização de novas e profundas mudanças no arranjo organizacional do sistema internet. A de maior impacto na sua governança foi anunciada em junho de 1998 pelo Departamento de Comércio dos EUA, em documento que ficou conhecido como White paper. Dele constavam diversas diretrizes, entre as quais merece destaque a firme intenção do governo norte-americano de "desestatizar" o sistema de nomes de domínio, dele se desligando, e de deixar sua coordenação a uma corporação privada, sem fins lucrativos.

É preciso, contudo, esclarecer o sentido dessa “desestatização", já que o sistema internet nunca fora efetivamente de propriedade estatal. O estado, enquanto financiador de projetos de pesquisa, de fato influenciava sua organização. Mas disso não se extrai que sobre ele tinha propriedade ou que poderes de autoridade pública tivessem sido usados para criar o sistema. A ação estatal, no caso, era típica de uma "administração de fomento" ou, no máximo, de uma "administração prestadora", mas não de uma "administração pública reguladora".

Segundo consta do White paper, o governo dos EUA, no processo de mudança da governança do sistema, se limitaria a reconhecer a nova corporação, que deveria ser efetivamente constituída por grupos interessados na internet (não só aqueles situados nos EUA, mas em todo o mundo), incluindo a comunidade de técnicos. ${ }^{18}$

Na esteira do que fora anunciado pelo White paper, instituiu-se, em 30 de setembro de 1998, sob as leis do estado da Califórnia, nos EUA, a Internet Corporation for Assigned Names and Numbers (Icann), organização que veio a assumir o posto de coordenadora máxima do sistema internet no mundo. ${ }^{19}$

A Icann foi constituída sob a forma de organização não estatal de direito privado, sem fins lucrativos, tendo como missão primordial promover, no interesse global, a estabilidade operacional da internet por meio: 1) da coordenação da atribuição de parâmetros técnicos da internet necessários à manutenção da sua conectividade universal; 2) do exercício e da supervisão

18 Confira-se excerto do documento em questão: “O Governo dos EUA está preparado para reconhecer, ao entrar em acordo com (e buscar apoio internacional para) uma nova corporação, sem fins lucrativos, formada por atores privados da Internet para administrar a política pública do sistema de nomes e de endereços da Internet. Sob este(s) acordo(s) ou entendimento(s), a nova corporação assumiria diversas responsabilidades pela administração do sistema de nomes de domínio atualmente administrado por ou em nome do Governo dos EUA ou por terceiros contratados pelo Governo dos EUA" (tradução livre).

19 A Icann, apesar de formalmente constituída em 30 de setembro de 1998, ganhou suas feições atuais aos poucos, no curso de um longo e complexo processo de formação. 
de funções relacionadas à coordenação do espaço de endereços IP; e 3) do exercício e da supervisão de funções relacionadas à coordenação do espaço de nomes de domínio da internet (DNS), incluindo o desenvolvimento de políticas para a determinação das circunstâncias sob as quais novos domínios de primeiro nível (TLDs) seriam acrescentados à raiz do sistema DNS. ${ }^{20}$ Noutras palavras, a Icann passou a ser responsável pela alocação de endereços de protocolos internet (IPs), pela coordenação dos gTLDs e dos ccTLDs, e pela administração da raiz do sistema internet, substituindo-se nas funções antes desempenhadas pela Iana.

Interessante é que, mesmo sendo uma organização não estatal gerindo um sistema também não estatal, a Icann se organizou a partir de princípios e objetivos de interesse coletivo, e não como um clube privado, destinado a realizar interesses e gerar benefícios para seus membros instituidores. Ela surgiu, portanto, como uma entidade de espírito público, e com uma estrutura coerente com esse espírito.

Com a finalidade de promover uma gestão do sistema internet horizontal e permeável às visões e opiniões do setor, imaginou-se para a Icann um modelo de governança singular, do tipo bottom-up, consensus-driven, multistakeholder. ${ }^{21}$ Bottom-up porque se quis abrir espaço para a adoção de medidas não impositivas (da base para o topo), ou seja, advindas de demandas de membros de grupos interessados na internet (e no seu bom funcionamento); consensusdriven porque se quis que as decisões relativas à política do interesse público do sistema internet - recurso vital para a coletividade contemporânea - fossem tomadas com base em consenso (ou no maior grau de consenso possível); multistakeholder porque se quis que participassem efetiva e ativamente da Icann membros dos mais variados grupos que eventualmente tivessem interesse na internet e no seu bom funcionamento - fazem parte da comunidade da Icann organizações responsáveis pelo registro de nomes de domínio, provedores, defensores de propriedade intelectual, de interesses comerciais, não comerciais e sem fins lucrativos, mais de 100 governos distintos e incontáveis usuários da internet.

Subjaz à criação da Icann a intenção de promover uma gestão do sistema internet partilhada entre todos aqueles que globalmente estariam sujeitos

20 Tradução livre do art. 3o do documento constitutivo do Icann intitulado "Articles of incorporation". Para informações completas e detalhadas sobre a constituição da Icann e sobre sua estrutura e funcionamento, consultar David Lindsay, International domain name law - Icann and the UDRP, op. cit., p. 64 e ss.

${ }^{21}$ Informações colhidas do sítio eletrônico da Icann (www.icann.org). 
às suas decisões, desvencilhada dos Estados nacionais - lembre-se que a internet, naquele momento, já havia ganhado o mundo e deixado de ser um experimento de interesse exclusivo de um grupo de pesquisadores.

A verdade é que a estratégia de transformar a governança da internet em um esforço de corregulação - permitindo que suas políticas fossem fixadas por ampla participação e consenso dos sujeitos por ela atingidos decorreu, quase que naturalmente, da transmutação da internet em um "bem" genuinamente global e coletivo. Afinal, se o sistema internet é de todos, faz sentido que suas políticas - para realmente serem legítimas, efetivas e eficazes - sejam fruto de um trabalho igualmente global e coletivo. Parece não haver espaço nesse contexto para a tomada de decisões unilaterais, apenas em favor de sujeitos específicos.

No plano operacional, a Icann conta com a colaboração de uma série de organizações, de tipos distintos, que com ela não se confundem. Funcionam como prolongamentos da Icann, como seus agentes, atuando em seu nome no desempenho de funções variadas.

Em relação à gestão dos TDLs, por exemplo, há organizações autorizadas pela Icann a registrar novos nomes de domínio sob gTLDs, tais como o ".com", ${ }^{22}$ e, outras, autorizadas a administrar os ccTLDs, tais como o ".br". ${ }^{23}$ Há, ainda, organizações regionais - a exemplo do American Register for Internet Numbers Ltd (Arin), do Latin American and Caribbean Internet Addresses Registry (Lacnic) e do African Network Information Center (Afrinic) - , voltadas à distribuição de números IP em suas áreas de influência. O Lacnic, apesar de abarcar o Brasil, delegou ao CGI.br a responsabilidade pela alocação e administração de endereçamentos IPs no território brasileiro. ${ }^{24}$

Há um emaranhado de organizações responsáveis pela gestão integrada do sistema internet, e elas estão espalhadas por todo o mundo. Todas elas são, de um modo ou de outro, vinculadas à Icann e às suas políticas (algumas com mais, outras com menos autonomia em relação à coordenadora central). A verticalização do sistema é fundamental para sua operação em escala global.

22 Há centenas de organizações autorizadas pela ICANN a realizar registros sob gTLDs. A lista completa das organizações pode ser conferida neste link: http://www.internic.net/origin.html.

23 A lista completa de administradores de ccTLDs pode ser conferida no link a seguir: <www. iana.org/domains/root/db>.

24 Cf. NEVES, Kelli Priscila Angelini. Nomes de domínio e o sistema administrativo de conflitos de internet. Dissertação (mestrado) - Pontifícia Universidade Católica, São Paulo, 2013. p. 70. 


\section{Modelo de governança do sistema internet no Brasil}

\subsection{0 início do ".br"}

Os Country Code Top-level Domains (ccTLDs), como visto, representam o topo da estrutura de domínio para uma determinada região em geral correspondente a um código de país. Justamente com os Generic Top-level Domains (gTLDs) compõem o que se convencionou chamar de domínios de primeiro nível (Top-level domains - TLDs).

Os ccTLDs, criados a partir da observação de que a internet consistia em empreendimento essencialmente global, foram atribuídos às mais variadas regiões do globo de maneira bastante peculiar: ${ }^{25}$

Os ccTLDs, criados com base na tabela ISO 3166, foram sendo repassados pelo Iana - Internet Assigned Numbers Authority a quem os solicitava, de maneira bem informal, sem que, necessariamente, houvesse qualquer vínculo com o governo de cada um dos países correspondentes, posto serem, desde seu surgimento, desvinculados de questões governamentais ou políticas. As entidades que receberam a concessão do registro de nomes de domínio nos ccTLDs pertencem, quase que em sua totalidade, à área acadêmica ou à iniciativa privada, na sua maioria ONGs - Organizações não Governamentais sem fins lucrativos" ${ }^{26}$

Além de o processo de atribuição de ccTLDs ter sido informal - no sentido de que não envolveu qualquer trâmite de cunho político - , ele não era focado somente em análises sobre a capacidade técnica da pessoa ou da entidade solicitante. Para a efetivação da concessão pela Iana, além do estabelecimento de um vínculo de mútua confiança, era preciso que a pessoa

25 Os ccTLDs, ao contrário do que o próprio nome poderia sugerir, nem sempre remetem a Estados nacionais. Há ccTLDs que dizem respeito a territórios ou a regiões geográficas específicas (e não necessariamente a Estados). Confira-se definição de ccTLDs dada pelo glossário do próprio sítio eletrônico da ICANN: "Domínios escritos com duas letras, tais como .uk (United Kingdom) e .jp (Japão), são chamados de country code top-level domains (ccTLDs) e correspondem a países, territórios ou outras localidades geográficas (...)" (tradução livre).

26 Kelli Priscila Angelini Neves, Nomes de domínio e o sistema administrativo de conflitos de internet, op. cit., p. 76. Esse trabalho é base das informações deste tópico. 
fosse cidadã do país correspondente - ou que a entidade solicitante fosse sediada naquele país. $\mathrm{O}$ caso do Brasil não foi exceção. ${ }^{27}$

O ccTLD ".br" foi solicitado à Iana em 1989 diretamente por Demi Getschko, uma das figuras mais importantes da internet no Brasil. Getschko à época gerenciava o Data Center da Fundação de Amparo à Pesquisa do Estado de São Paulo (Fapesp) e era responsável, juntamente com outros pesquisadores, por atividades na área de redes digitais internacionais (precursora da internet). ${ }^{28}$

No caso brasileiro, portanto, a gestão do ccTLD ".br" foi delegada, pela entidade global, a Iana, a um grupo específico de pessoas que, por acaso, estava alocado na Fapesp. Não houve, assim, qualquer envolvimento do Estado brasileiro - seja por meio da União, seja mesmo do estado de São Paulo, de cuja administração indireta a Fapesp faz parte - no processo de incorporação do território brasileiro ao sistema internet, apesar de a administração do ".br" formalmente ter ficado sob responsabilidade da Fapesp. Tratou-se, isto sim, de um acordo quase que personalíssimo, viabilizado mais em função de relações pessoais de confiança, do que de relações institucionais.

A delegação do ".br" ao grupo de pesquisadores foi feita antes mesmo de as primeiras conexões internet no Brasil serem ativadas, algo que só viria a ocorrer no início da década de 1990. A despeito de a concessão do ccTLD ter sido realizada no ano de 1989, só em 1994 chegariam à Fapesp os primeiros pedidos de registro de nomes de domínio sob o “.br" - a maior parte deles advindos de universidades e instituições de pesquisa.

\subsection{Características do modelo de governança do sistema internet no Brasil}

A governança do sistema internet no Brasil de início era bastante simples. A alocação de endereços IP e a gestão do domínio “.br" eram realizadas pelos pesquisadores sediados na Fapesp, a quem a gestão do ccTLD havia sido

27 A análise retrospectiva dos fatos deve levar em conta que a internet, naquele momento (final da década de 1980), ainda era um experimento inconcluso, incipiente e de potencial desconhecido. A gestão de nomes de domínio não continha em si valor comercial. Consistia, isso sim, em ônus a quem a solicitava.

28 O perfil de Demi Getschko pode ser consultado nos links a seguir: <http://ccnso.icann.org/ about/bio/demi-getschko.htm> e <http://internethalloffame.org/inductees/demi-getschko>. 
confiada diretamente pela Iana. Por determinação do grupo, os interessados em registrar nomes de domínio sob o ".br" tinham de seguir algumas diretrizes básicas: apresentar os dados do solicitante, o nome de domínio desejado e cópia do cartão do Cadastro Nacional de Pessoa Jurídica (CNPJ). O “.br", portanto, desde o princípio esteve fechado para estrangeiros; só empresas com CNPJ poderiam obter nomes de domínio sob o ". br". ${ }^{29}$

A rápida expansão e popularização da internet, no entanto, conduziu à revisão do modelo de governança do sistema internet no Brasil. O próprio governo brasileiro, antes alheio à operação do sistema internet em território nacional, passou a demonstrar interesse em acompanhar seu desenvolvimento e em contribuir para seu aperfeiçoamento.

Foi nesse momento que Demi Getschko e representantes do Ministério das Comunicações e da Ciência e Tecnologia decidiram unir representantes de áreas ligadas à internet e ao governo para integrarem uma nova organização, voltada a acompanhar o provimento de serviços, estabelecer recomendações, emitir pareceres, coletar, disseminar e organizar informações sobre atividades relacionadas à internet no Brasil.

A criação dessa organização e a assunção, por ela, das tarefas mencionadas não decorreram de deliberação e de delegação estatais. A União Federal não tinha competência própria na matéria, pois o sistema é global, sua coordenação global estava a cargo da Iana e esta não conferira ao governo brasileiro qualquer função de agente desse sistema. Ademais, sendo o sistema internet um serviço de valor adicionado - que, pela Lei Geral de Telecomunicações, desenvolve-se como atividade não estatal livre, não sujeita à regulação própria dos serviços públicos - , o Poder Executivo Federal não teria título jurídico para assumir como suas tarefas ligadas à gestão desse sistema. Foi o agente da Iana no Brasil quem tomou a iniciativa de propor ao governo uma aproximação, de modo que o Estado também passasse a influir na governança a partir de então - sem, no entanto, estatizar o sistema. Esse foi o ajuste que o governo aceitou e apoiou.

A ideia ganhou contornos mais bem delimitados com a edição da Portaria Interministerial no 147, de 31 de maio de 1995, documento que

29 Vale ressaltar que nem todos os administradores de ccTLDs pelo mundo adotaram o mesmo tipo de política. O operador do ccTLD da República Dominicana, por exemplo, não estabeleceu esse tipo de exigência para inscrição de nomes de domínio sob o domínio ".do", permitindo que os residentes de quaisquer países livremente se cadastrassem sob o nome de domínio ligado ao território desse país. 
formalizou a criação do Comitê Gestor da Internet do Brasil, o CGI.br. ${ }^{30}$ O comitê seria composto por uma série de membros distintos com interesses variados na internet - representantes do governo, de entidades de pesquisa, da comunidade acadêmica, de provedores de serviços, da comunidade empresarial e da comunidade de usuários da internet (art. $2^{\circ}$ ). A ideia era que todos esses grupos, em conjunto, pudessem influir e deliberar sobre os rumos do ".br" e do sistema internet no Brasil. Foi, portanto, um prenúncio do modelo de governança pluriparticipativo e não estatal, que posteriormente viria a ser adotado até mesmo pela Icann.

A portaria não atribuiu ao comitê o status de órgão público, nem, portanto, o integrou à administração pública. A portaria apenas marcou a criação de uma organização não estatal, sem personalidade jurídica (um simples colegiado), tornando conhecido um fato implícito: o de que essa organização havia sido aceita como agente da entidade global de coordenação da internet. Essa aceitação pela Iana ocorreu de forma tácita, no estilo informal que marca as entidades não estatais, não existindo, portanto, um ato formal do Iana nomeando o novo colegiado brasileiro, o CGI.br, como seu delegado para o registro de nomes de domínio ".br". Mas essa aceitação tácita foi inequívoca, pois o CGI.br de fato sucedeu as pessoas físicas que até então atuavam no Brasil como agentes do Iana.

A portaria interministerial, que registrara publicamente o fato de que o CGI.br estava assumindo a tarefa de coordenar o registro de nomes de domínio, foi mencionada pelo próprio comitê, em momento posterior, quando editou a sua Resolução n⿳0 002/98, atribuindo à Fapesp a tarefa de concretamente registrar nomes de domínio sob o ".br", de distribuir endereços IPs e de realizar a manutenção na rede eletrônica internet.

30 Portaria Interministerial no 147/1995:

"Art. 1‥ Criar o comitê Gestor da Internet, que terá como atribuições:

I - acompanhar a disponibilização de serviços Internet no país;

II - estabelecer recomendações relativas a: estratégia de implantação e interconexão de redes, análises e seleção de opções tecnológicas, e papéis funcionais de empresas, instituições de educação, pesquisa e desenvolvimento (IEPD);

III - emitir parecer sobre a aplicabilidade de tarifa especial de telecomunicações nos circuitos por linha dedicada, solicitados por IEPDs qualificados;

IV - recomendar padrões, procedimentos técnicos e operacionais e código de ética de uso, para todos os serviços Internet no Brasil;

V - coordenar a atribuição de endereços IP (Internet Protocol) e o registro de nomes de domínios;

VI - recomendar procedimentos operacionais de gerência de redes;

VII - coletar, organizar e disseminar informações sobre o serviço Internet no Brasil; e

VIII - deliberar sobre quaisquer questões a ele encaminhadas". 
O que se nota é que os documentos jurídicos em comento - portaria interministerial e resolução - foram apenas veículos para reafirmar, formalizar e divulgar situação de fato já consolidada - afinal, a Fapesp, desde 1989, já era a pessoa jurídica que figurava como a responsável pela distribuição de IPs e pelo registro de nomes de domínio sob o ".br".

Nova mudança na governança do sistema internet no Brasil viria a ser formalizada por meio do Decreto Federal no 4.829, de 3 de setembro de 2003. O referido decreto, sob diversos aspectos, assemelha-se à portaria interministerial - inclusive ao repetir a fórmula "fica criado o Comitê Gestor da Internet no Brasil", a despeito de, ao tempo da sua elaboração, ele já existir e funcionar. Em linhas gerais, as modificações concentraram-se no próprio fato de o CGI.br passar a ter previsão em diploma normativo mais robusto decreto, e não portaria - , nas suas atribuições e na sua composição. ${ }^{31}$

31 Decreto Federal no 4.829/2003:

"Art. 1․ Fica criado o Comitê Gestor da Internet no Brasil - CGI.br, que terá as seguintes atribuições:

I - estabelecer diretrizes estratégicas relacionadas ao uso e desenvolvimento da Internet no Brasil;

II - estabelecer diretrizes para a organização das relações entre o Governo e a sociedade, na execução do registro de Nomes de Domínio, na alocação de Endereço IP (Internet Protocol) e na administração pertinente ao Domínio de Primeiro Nível (ccTLD - country code Top Level Domain), ".br"', no interesse do desenvolvimento da Internet no País;

III - propor programas de pesquisa e desenvolvimento relacionados à Internet, que permitam a manutenção do nível de qualidade técnica e inovação no uso, bem como estimular a sua disseminação em todo o território nacional, buscando oportunidades constantes de agregação de valor aos bens e serviços a ela vinculados;

IV - promover estudos e recomendar procedimentos, normas e padrões técnicos e operacionais, para a segurança das redes e serviços de Internet, bem assim para a sua crescente e adequada utilização pela sociedade;

$\mathrm{V}$ - articular as ações relativas à proposição de normas e procedimentos relativos à regulamentação das atividades inerentes à Internet;

VI - ser representado nos fóruns técnicos nacionais e internacionais relativos à Internet;

VII - adotar os procedimentos administrativos e operacionais necessários para que a gestão da Internet no Brasil se dê segundo os padrões internacionais aceitos pelos órgãos de cúpula da Internet, podendo, para tanto, celebrar acordo, convênio, ajuste ou instrumento congênere; VIII - deliberar sobre quaisquer questões a ele encaminhadas, relativamente aos serviços de Internet no País; e

IX - aprovar o seu regimento interno.

Art. 2․ . O CGI.br será integrado pelos seguintes membros titulares e pelos respectivos suplentes:

I - um representante de cada órgão e entidade a seguir indicados:

a) Ministério da Ciência e Tecnologia, que o coordenará;

b) Casa Civil da Presidência da República;

c) Ministério das Comunicações;

d) Ministério da Defesa;

e) Ministério do Desenvolvimento, Indústria e Comércio Exterior;

f) Ministério do Planejamento, Orçamento e Gestão; 
O decreto, na esteira da portaria interministerial, mencionou a "criação" do comitê, uma organização sem personalidade jurídica. Mas, novamente, o CGI.br não recebeu do decreto o status de órgão público, nem foi integrado à administração pública federal. Continuou sendo o que já era: um organismo não estatal e sem personalidade jurídica, atuando como agente da entidade de coordenação global da internet, por delegação tácita desta. Além disso, o decreto formalizou a consolidação do modelo pluriparticipativo e multissetorial de governança do sistema internet no Brasil, imaginado para permitir gestão compartilhada do ".br" e dos rumos do sistema internet em território nacional.

Vê-se que o CGI.br, também nos moldes indicados no decreto federal, não é majoritariamente ocupado por membros do governo; ao contrário, é predominantemente integrado por membros da sociedade civil. Essa escolha não se deu ao acaso: a ideia é que o CGI.br fosse organização não estatal com participação estatal, mas que não pertencesse a ninguém (nem mesmo ao Estado). Sua forma de composição buscou refletir o próprio espírito da internet, plural e coletivo.

Em suma, nem a primitiva portaria nem o posterior decreto tiveram a natureza de atos constitutivos, que realmente criassem organizações e lhes atribuíssem poderes. A portaria e o decreto tiveram natureza de simples atos declaratórios, que reconhecem um fato e o divulgam para conhecimento público.

Desde a implantação do sistema internet no Brasil até o ano de 2005 vinha competindo à Fapesp, como pessoa jurídica em que atuavam os agentes do coordenador global, por questões históricas, o registro de nomes de domínio sob o ".br" e a distribuição de endereços IP em território nacional. Mas, com a expansão da internet - e da quantidade de nomes de domínio registrados sob o ".br" - aos poucos foi deixando de fazer sentido que a Fapesp, instituição vocacionada à pesquisa, continuasse a administrar a distribuição de IPs e o registro de nomes de domínio - funções que há muito haviam se distanciado das suas atividades-fim.

\footnotetext{
g) Agência Nacional de Telecomunicações; e

h) Conselho Nacional de Desenvolvimento Científico e Tecnológico;

II - um representante do Fórum Nacional de Secretários Estaduais para Assuntos de Ciência e Tecnologia;

III - um representante de notório saber em assuntos de Internet;

IV - quatro representantes do setor empresarial;

$\mathrm{V}$ - quatro representantes do terceiro setor; e

VI - três representantes da comunidade científica e tecnológica".
} 
Por essas e por outras razões os membros do CGI.br, após longo período de avaliação, estudos e debates sobre a matéria, decidiram, mais uma vez com a aquiescência tácita da coordenadora global do sistema, instituir uma pessoa jurídica não estatal de direito privado, sem fins lucrativos, para ser a entidade exclusivamente responsável pelo registro de nomes de domínio e de alocação de endereços IP, bem como pela manutenção desta estrutura no Brasil. Surgia, assim, o Núcleo de Informação e Coordenação do Ponto BR (NIC.br), organização privada sem fins lucrativos instituída para servir de braço executor do CGI.br, como delegada de fato da Icann.

O NIC.br, como o próprio CGI.br, tem composição plural. Dele fazem parte, ocupando funções variadas, membros e ex-membros do CGI.br, membros representantes do governo e membros da sociedade civil, escolhidos entre pessoas de reconhecido conhecimento e competência nas áreas de atividades relacionadas com os objetivos estatutários do NIC.br. ${ }^{32}$

Suas atribuições e objetivos, conforme consta do seu estatuto social, são múltiplas e diversificadas. A ele compete: 1) registrar nomes de domínio de primeiro nível; 2) distribuir endereços de IP; 3) operar computadores, servidores de rede e toda a infraestrutura necessária, de modo a garantir a boa funcionalidade da operação de registro e manutenção dos domínios sob o “.br";4) atender aos requisitos de segurança e emergência na internet brasileira em articulação e cooperação com as entidades e os órgãos responsáveis; 5) desenvolver projetos que visem melhorar a qualidade da internet no Brasil e disseminar seu uso; 6) fomentar e acompanhar a disponibilização e a universalização de serviços de internet no país; e 7) promover ou colaborar na realização de cursos, simpósios, seminários, conferências, feiras e congressos, visando contribuir para o desenvolvimento e o aperfeiçoamento do ensino e dos conhecimentos nas áreas de suas especialidades.

Em 14 de fevereiro de 2006, o CGI.br, por meio da edição da Resolução no 001/2005, veio a formalizar a operação do sistema internet no Brasil pelo NIC.br, transformando-o oficialmente em seu longa manus ${ }^{33} \mathrm{e}$, assim, por via da aceitação tácita, como longa manus da Icann.

32 Para o estatuto social do NIC.br: <http://www.nic.br/estatuto/index.htm>.

33 A íntegra da Resolução no 001/2005 pode ser consultada no link a seguir: <http://cgi.br/ resolucoes/documento/2005/001>. 


\section{Avaliação da juridicidade do modelo de governança do sistema internet no Brasil}

A gestão do sistema internet no Brasil - englobando as funções de atribuição de números IP em território nacional, de registro de nomes de domínio sob o ".br" e de operação e manutenção da infraestrutura ligada à internet - , conquanto normalmente tida por eficaz, tem suscitado dúvidas pontuais quanto à consistência de seu modelo de governança.

A primeira delas contesta a criação do CGI.br por decreto. Segundo críticos, o CGI.br, tal como moldado pelo decreto federal, seria uma espécie de órgão regulador da internet no Brasil, dotado de poderes para restringir relações privadas. Por assumir a feição de órgão regulador, deveria ter sido instituído por lei formal. O Decreto no 4.829, de 2003, seria, assim, uma espécie de decreto autônomo (sem base legal), não admitido por nosso direito. ${ }^{34}$

$\mathrm{O}$ segundo questionamento acerca do modelo de governança do sistema internet no Brasil recai sobre sua legitimidade. Pelo fato de o CGI. br ser composto por membros não dotados de mandato popular, faltar-lheia legitimidade para, como suposto órgão público regulador da internet, "interferir no domínio econômico". ${ }^{35}$

A terceira crítica refere-se à especial conexão entre o modelo de governança do sistema internet no Brasil e a Icann. O sistema brasileiro, por ser peça de um todo mais amplo administrado pela Icann, estaria, ainda que indiretamente, sujeito à influência do governo norte-americano. Isso porque a Icann - órgão que segundo os críticos teria sido investido de poderes pelos EUA - atuaria de forma impositiva (e não consensual, como propalado) sobre todo o sistema internet. Em face desse cenário, apesar de a gestão de domínios de topo com códigos de país integrar a gestão global da internet, o mais adequado, à luz do interesse nacional, seria que ela ficasse sob a responsabilidade de ente estatal. ${ }^{36}$

${ }^{34}$ Crítica neste sentido é exposta por Andrey Vilas Boas de Freitas e Igor Vilas Boas de Freitas, Os novos mercados de nomes e números da internet - reestruturação do sistema de governança brasileiro, op. cit., p. 16 e ss.

35 Ibid., p. 15 e ss.

36 Crítica nesse sentido é feita por GONÇALVES, Pedro. Regulação administrativa da internet. Revista de Direito Público da Economia - RDPE, Belo Horizonte, ano 1, n. 1, p. 195 e ss., jan/mar. 2003. 


\subsection{A governança do sistema internet no Brasil não envolve o exercício de competências estatais e por isso seu modelo dispensa previsão legal}

Ao se observar o conteúdo do art. 1ํ do Decreto Federal no 4.829 , de 2003, constata-se que, de fato, foi previsto que o CGI.br iria, ao menos em tese, influir na política do sistema internet no país, competindo-lhe, por exemplo, fixar "diretrizes estratégicas relacionadas ao desenvolvimento da Internet no Brasil" (inciso I), "estabelecer diretrizes para a organização das relações entre o Governo e a sociedade, na execução do registro de Nomes de Domínio, na alocação de Endereço IP (Internet Protocol) e na administração pertinente ao Domínio de Primeiro Nível, '.br', no interesse do desenvolvimento da Internet no País" (inciso II) e "propor programas de pesquisa e desenvolvimento relacionados à Internet, que permitam a manutenção do nível de qualidade técnica e inovação no uso, bem como estimular a sua disseminação em todo o território nacional, buscando oportunidades constantes de agregação de valor aos bens e serviços a ela vinculados" (inciso III).

Não só no plano abstrato parece fazer sentido a afirmação de que o CGI. br funcionaria como uma espécie de ordenador do sistema internet no Brasil. No plano concreto, o CGI.br, ao que tudo indica, realmente tem cumprido esse papel, atuando, desde a sua instituição, de modo a contribuir para a formatação do modelo de governança do sistema internet no Brasil e para direcionar sua operação na prática. Citamos dois exemplos.

O primeiro deles, já referido neste estudo, diz respeito à Resolução no $001 / 2005$, de 14 de fevereiro de 2006. Esse diploma normativo foi importante para a delimitação do atual modelo de governança do sistema internet no Brasil, pois formalizou a atribuição de o NIC.br executar o registro de nomes de domínio, alocar endereços IP e administrar o domínio de primeiro nível “.br" (art. 1ํㅜ). Além disso, a resolução, em seu art. 3ํㅡㄹ definiu que o NIC.br poderia cobrar pelo desempenho de suas atividades, em "valores compatíveis com os vigentes internacionalmente, mediante prévia aprovação do CGI.br", tendo de integralmente revertê-los para o ressarcimento de suas despesas e para o fomento de atividades ligadas ao desenvolvimento da internet no Brasil (art. 4을.

O segundo exemplo consubstanciou-se na Resolução no CGI.br/ RES/2008/008/P, de 28 de novembro de 2008, voltada ao estabelecimento de procedimentos para registro de nomes de domínio. Nela se decidiu, por exemplo, que nomes de domínio disponíveis para registro seriam concedidos 
aos primeiros requerentes, desde que satisfizessem exigências mínimas também previstas na resolução (art. 1으, parágrafo único).$^{37}$

Ao que parece, portanto, o CGI.br, à luz das tarefas que formalmente assumiu e do modo como as vem concretamente desempenhando, tem se firmado como órgão regulador não estatal, isto é, como uma organização que define o modo como devem se comportar os sujeitos que pretendam ingressar e se manter no sistema internet.

Esse fato, de o CGI.br ordenar e coordenar o sistema internet no Brasil, desempenhando papel de órgão regulador não estatal, é, por si só, suficiente para que sua criação obrigatoriamente dependesse da edição de lei formal? Faz sentido exigir que todo e qualquer tipo de organização voltada a ordenar, coordenar ou disciplinar setores ou nichos específicos obrigatoriamente seja instituída por lei em sentido estrito?

A verdade é que nem toda organização dotada de papel regulatório (em sentido amplo) precisa, necessariamente, ter previsão legal - aliás, a experiência brasileira tem exemplos de entes reguladores que sequer contam com previsão em decreto. ${ }^{38}$

$\mathrm{O}$ argumento de que o CGI.br, para que pudesse licitamente existir e desenvolver suas atividades, deveria ter sido criado e disciplinado por lei formal parte da premissa de que ao comitê teriam sido transferidas competências exclusivas do Estado brasileiro. Fosse a premissa verdadeira, o raciocínio em tese faria sentido. Afinal, atividades próprias ou exclusivas do Estado realmente só podem ser transferidas a outros entes mediante delegação expressa, calcada em lei ou, eventualmente, na própria Constituição.

Veja-se o exemplo das telecomunicações. Disse o Texto Constitucional que compete à União "explorar, diretamente ou mediante autorização, concessão ou permissão, os serviços de telecomunicações, nos termos da lei, que

37 A resolução, no seu art. 4º, determinou que para a efetivação do registro de nome de domínio o requerente deveria, por exemplo, fornecer nome empresarial, número de CNPJ, endereço físico e eletrônico, nome do responsável e número de telefone (caso o solicitante fosse pessoa jurídica) e nome completo, número de $\mathrm{CPF}$, endereços físico e eletrônico e número de telefone (caso o solicitante fosse pessoa física).

38 O Conselho Nacional de Autorregulamentação Publicitária (Conar), por exemplo, não está previsto em lei alguma, a despeito de inequivocamente disciplinar, inclusive por meio de decisões concretas, atores ligados à publicidade no Brasil. A Associação Brasileira das Entidades dos Mercados Financeiro e de Capitais (Anbima) é outro exemplo de ente dotado de poderes para regular, inclusive por meio de normas, desprovido de previsão legal. O Conar e a Anbima são entidades voltadas a um tipo específico de regulação (denominado autorregulação) e pautam suas condutas por códigos e procedimentos não previstos em lei. Entes autorreguladores, por desenvolverem regulação privada, normalmente não têm base legal. 
disporá sobre a organização dos serviços, a criação de um órgão regulador e outros aspectos institucionais" (art. 21, XI). Em cumprimento ao comando constitucional, editou-se a Lei Geral de Telecomunicações (Lei no 9.472, de 1997), responsável, entre outras coisas, por criar a Anatel (art. 8o), a ela delegando a competência para concretamente disciplinar certos aspectos dos serviços de telecomunicações (art. 19).

Nesse caso, poderia a União ter optado por instituir órgão regulador via decreto presidencial? A resposta evidentemente é "não". O Texto Constitucional, ao atribuir à União a competência para explorar os serviços de telecomunicações, inequivocamente os definiu como atribuição própria, exclusiva, do Estado. Nessa hipótese, mesmo que a Constituição tivesse sido silente sobre o tema, a União só poderia licitamente atribuir a competência para disciplinar os serviços de telecomunicações por meio de diploma legal.

Há um elemento em relação aos serviços de telecomunicações que viabilizou que a norma constitucional os incluísse entre as competências próprias do Estado. Esse tipo de serviço, diferentemente do sistema internet, não nasceu como empreendimento global; nasceu como empreendimento puramente nacional, de início voltado a conectar pontos geográficos distintos dentro de uma mesma municipalidade. Sempre foi fortemente dependente e atrelado ao Estado, desde o princípio tratado como um serviço público. E isso por uma razão simples: o desenvolvimento e a expansão destes serviços exigiram - e em alguns casos ainda exigem - forte envolvimento estatal, haja vista os pesados investimentos que eram necessários para o desenvolvimento de infraestrutura (cabos, aparelhos, estações etc.).

Todavia, no caso da regulação do sistema internet, não estão em jogo atribuições próprias, exclusivas do Estado, tal como no exemplo dos serviços de telecomunicações. O sistema internet e sua regulação nunca estiveram inseridos no bojo de atribuições propriamente estatais. $\mathrm{O}$ estado nunca se ocupou - nem esteve obrigado a se ocupar - do registro de nomes de domínio, da gestão de domínio de primeiro nível “.br" e da distribuição de endereços IP; essas atividades jamais foram percebidas como próprias do Estado brasileiro, como parte integrante de um empreendimento de cunho nacional.

A incorporação do território brasileiro ao sistema internet global ocorreu sem qualquer envolvimento direto do Estado; por mais singelo que possa parecer, esse movimento foi fruto direto de interações pessoais estabelecidas entre acadêmicos brasileiros e estrangeiros envolvidos em pesquisas sobre conexão de computadores em redes. 
De fato, houve um tempo em que o sistema internet no Brasil foi gerido formalmente pela Fapesp - agência de fomento à pesquisa pertencente à administração pública do estado de São Paulo. Recorde-se, contudo, que a assunção dessa atividade pela fundação não se deu por título próprio, mas por delegação externa, já que o grupo de pesquisadores que havia obtido autorização da Iana para distribuir números IP e administrar o domínio de primeiro nível ".br" em território nacional calhou de lá estar alocado. Não houve, em verdade, a assunção de atividades e competências pela própria instituição Fapesp, mas por pesquisadores - pessoas físicas, portanto - que a integravam.

Todo esse arranjo se viabilizou e se manteve no Brasil porque a legislação assegurou liberdade para a implantação de serviços de valor adicionado (hoje expressamente prevista no art. 61 da Lei Geral de Telecomunicações). Assim, as pessoas e entidades que, articuladas com a entidade global coordenadora, assumiram no Brasil a tarefa de cuidar do sistema internet, o fizeram no exercício de uma liberdade de empreender assegurada por lei. Embora de interesse público, dadas a dimensão e a importância que o sistema internet acabou assumindo com o tempo, tanto o estabelecimento de regras de funcionamento do sistema como sua posterior execução são atividades de regulação privada. Nem o CGI.br nem o NIC.br fazem regulação pública, assumindo poderes ou privilégios públicos. Sua atuação, como gestores do sistema internet, ocorre no exercício da liberdade de empreender no campo dos serviços de valor adicionado, sem a utilização de poder extroverso (isto é, de impor comportamentos compulsórios a ninguém) e sem a fruição de privilégio, exclusividade ou monopólio criados por lei (isto é, quaisquer outras pessoas podem inventar e implantar sistemas concorrentes, como serviços de valor adicionado).

É evidente, no entanto, que a atividade de regulação desenvolvida pelo CGI.br e pelo NIC.br tem grande impacto na vida concreta das milhões de pessoas, empresas e entidades que usam o sistema internet no Brasil. É uma regulação que juridicamente tem natureza privada, mas substancialmente tem importância pública. Em tese, essa circunstância poderia motivar o Estado brasileiro a, por meio evidentemente de lei, criar uma regulação exclusivamente estatal para criar condicionamentos jurídicos ao exercício dessa regulação privada, feita pelos responsáveis do sistema internet.

Mas o Estado brasileiro não se animou a adotar esse caminho. Qual a razão? 
Em primeiro lugar, não faria mesmo muito sentido querer tratar a regulação do sistema internet como atribuição própria e exclusiva de Estados nacionais individualizados. A internet e seu sistema, apesar de em sua fase embrionária terem surgido em projeto de um governo em específico, o dos EUA, logo ganharam vida própria, rompendo com quaisquer amarras geográficas. Não tardou para que a nova tecnologia revelasse que sua própria existência e funcionamento dependeriam de uma integração completa, transnacional. A razão de ser do sistema internet é viabilizar a criação de espaço de comunicação universal calcado em um mesmo padrão de linguagem.

O sistema internet é um empreendimento essencialmente global, de interesse coletivo. Seria um equívoco tratar sua dimensão local como matéria reservada ao Estado brasileiro - impedindo, assim, sua regulação por organização que não fosse de algum modo limitada por lei formal ou por um regulador público; fazê-lo importaria em ignorar a realidade (dos fatos e das normas) e todo o histórico do setor.

Em segundo lugar, a opção do Estado brasileiro por não criar uma regulação propriamente estatal sobre o sistema internet - deixando, portanto, que ele continue estruturado no modo que resultou da iniciativa dos agentes que, valendo-se da liberdade de empreender, incumbiram-se até aqui de sua implantação e gestão - decorre do reconhecimento da estrutura concebida por esses agentes.

O Estado brasileiro não cogitou de interferir autoritariamente no sistema internet. E isso não só por saber da inviabilidade de dominar nacionalmente um sistema global. Também por entender que essa intervenção não é necessária nem seria vantajosa, pois os valores públicos vêm sendo atendidos pela governança existente. E isso inclusive porque, embora seja uma governança a cargo de organismos não estatais, ela tem espaço para a participação e a influência das autoridades públicas relevantes ao assunto, a qual está prevista no arranjo formalizado pelo decreto.

Tudo isso veio depois a ser reconhecido em lei. O Marco Civil da Internet (Lei no 12.965 , de 2014), em seu art. 24, assim dispôs:

Art. 24. Constituem diretrizes para a atuação da União, dos Estados, do Distrito Federal e dos Municípios no desenvolvimento da internet no Brasil:

I - estabelecimento de mecanismos de governança multiparticipativa, transparente, colaborativa e democrática, com a participação do 
governo, do setor empresarial, da sociedade civil e da comunidade acadêmica;

II - promoção da racionalização da gestão, expansão e uso da internet, com participação do Comitê Gestor da internet no Brasil; (...).

Essas normas reconhecem o valor da regulação não estatal da internet, própria de um serviço de valor adicionado, feita pelo CGI.br (nominalmente mencionado), e mantêm a adesão do Estado à sua forma própria de governança: multiparticipativa, democrática, colaborativa e transparente. E mais: o art. 9으, $\S 1$ o da mesma lei determina que o presidente da República, ao exercer sua competência regulamentar sobre o importante tema da neutralidade de rede, que afeta a atuação dos prestadores de serviços de telecomunicações, ouça o Comitê Gestor da Internet, além da Anatel. É o reconhecimento, mais uma vez, da atuação desse organismo não estatal, que foi chamado, neste caso, a colaborar na informação do chefe do Poder Executivo, para que ele possa exercer uma competência que lhe é própria no campo das telecomunicações.

A formalização da existência do CGI.br por decreto, pelo fato de não envolver a delegação de poderes, atribuições ou competências estatais, era compatível com o ordenamento jurídico brasileiro.

O CGI.br e o NIC.br não são organizações estatais nem delegadas do Estado brasileiro. São agentes de um sistema coordenado por uma organização global sediada nos EUA, agentes que realizam tarefas integrantes de um sistema global. A internet não é empreendimento do Estado brasileiro, nem é empreendimento internacional criado por acordo de Estados nacionais. Ela é empreendimento global não estatal que pôde surgir e crescer pelo mundo afora valendo-se da liberdade que as normas de cada país deixaram a esse tipo de atividade. O que viabiliza o funcionamento desse sistema é uma rede de organizações pelo mundo, que criaram entre si relações de cooperação e coordenação.

Nem a Constituição nem a lei brasileira tentaram ou quiseram estatizar compulsoriamente o sistema internet no Brasil, o qual continua existindo entre nós como atividade desenvolvida com base na liberdade de empreender (Constituição Federal, art. 170, caput). De resto, uma estatização desse tipo só seria viável no Brasil se o coordenador global e as demais organizações espalhadas pelo mundo a aceitassem. O Estado brasileiro não teria como assumir por vontade exclusivamente sua um espaço que só existe em função da cooperação global. Faltar-lhe-iam meios para isso. 
Assim, CGI.br e NIC.br fazem regulação não estatal de um sistema não estatal, criado globalmente com base na liberdade de empreender. Essa regulação atinge os sujeitos que voluntariamente ingressam na internet e, portanto, aceitam submeter-se a ela. Não há "poder de polícia", não há atos de autoridade, não há relações de poder de natureza estatal. Não se trata, portanto, de regulação pública, instituída e disciplinada por lei.

\subsection{O decreto federal que formalizou a existência do CGI.br significou o apoio do Estado brasileiro a modelo não estatal de governança da internet no qual reconheceu valor}

A ramificação do sistema internet no Brasil seguiu trajetória interessante e desenvolveu uma governança inovadora - inclusive para os padrões internacionais. O modelo formalizado pelo Decreto Federal no 4.829, de 2003, de algum modo procurou reproduzir o espírito plural, coletivo, do próprio sistema internet. Buscou garantir que estivessem representados no comitê, responsável por dirigir a política pública não estatal do sistema internet no Brasil, os setores por ela diretamente afetados e que estivessem interessados em contribuir para aprimorá-la (governo, setor empresarial, terceiro setor, comunidade científica e tecnológica etc.).

O modelo de governança do sistema internet no Brasil não é puramente privado - no sentido de dirigido à realização apenas de interesses individuais -, tampouco estatal; conquanto não estatal, ele é pluralista, coletivo, conduzido pelo consenso de representantes da coletividade. Uma das vozes que encontram eco nesse modelo é a do Estado brasileiro, que dele participa - inclusive indicando o representante que tem função privilegiada no CGI.br (art. 2ํ, I, “a”) - sem, contudo, monopolizá-lo ou assumi-lo. O decreto, ao prever o CGI.br, deu origem à verdadeira organização de participação, moldada para desenvolver uma regulação não estatal.

A criação do CGI.br por decreto não objetivou torná-lo estatal. Essa foi a forma de o Estado aderir ao modelo de governança do sistema internet em território brasileiro - que, lembre-se, opera em escala global - , emprestandolhe apoio e legitimidade. Tratou-se, pois, de uma manifestação formal de que o Estado aceitava o arranjo institucional da governança do sistema internet no Brasil e que dele desejava fazer parte, acompanhando e influindo, em conjunto com outros atores relevantes, nos rumos da internet em território nacional. 
Ou seja, as autoridades brasileiras aceitaram a opção de gerir o sistema internet por meio de corregulação, pelo compartilhamento da competência regulatória não estatal entre os atores que poderiam contribuir para o desenvolvimento da internet no país. O Estado não quis, assim, tomar para si espaço essencialmente coletivo, razão pela qual é a administração pública que integra o CGI.br, e não o contrário.

Para tanto, as autoridades federais não precisaram de autorização legal expressa e específica. Estabelecer relações de cooperação institucional com entidades públicas ou privadas em matérias de interesse geral é algo que se inclui entre as competências gerais da União e de seus ministérios, segundo suas áreas de atuação, definidas atualmente na Lei Federal no 10.683 , de 28 de maio de 2003. Ao formalizar seu apoio e participação nessa organização, o CGI.br, a União exerceu competências que integram essas áreas de atuação legalmente previstas.

Esse tipo de organização de participação moldada para desenvolver regulação não estatal (composta por uma pluralidade de atores com interesses diversos - entre eles o próprio Estado) tem se multiplicado e ganhado importância crescente em todo o mundo. A literatura estrangeira as qualifica como modelos de administração híbridos, formados por governos e privados (hybrid intergovernmental-private administration). O grande exemplo normalmente invocado para ilustrá-los é a Icann - organização que tem governança em muitos aspectos semelhantes à do próprio CGI.br. ${ }^{39}$

Segundo teóricos do direito administrativo global, as tais organizações híbridas seriam especialmente adequadas ao espaço da administração global, distinto do espaço das relações interestatais (disciplinadas pelo direito internacional e normalmente travadas nos fóruns internacionais, como a Organização das Nações Unidas ou a Organização Mundial do Comércio), também distinto dos espaços regulatórios nacionais (disciplinado pelos direitos administrativos domésticos), porém um espaço formado por elementos característicos de ambos - o das relações interestatais e os regulatórios nacionais. ${ }^{40}$

A decisão do Estado brasileiro de aceitar e reconhecer organização de participação voltada ao desenvolvimento de regulação não estatal, aderindo à lógica global do sistema internet, não é singularidade nossa. A postura do

\footnotetext{
39 Cf. Benedict Kingsbury, Nico Krisch e Richard B. Stewart, The emergence of global administrative law, op. cit., p. 22.

40 Ibid., p. 26.
} 
Brasil se insere em tendência mundial, atrelada ao aparecimento de espaços administrativos globais (global administrative spaces).

E quanto à questão mais política, de que o Estado brasileiro estaria indiretamente se sujeitando à Icann e aos EUA, comprometendo sua própria soberania?

A Icann, apesar de sediada nos EUA e instituída com o impulso do governo norte-americano, com ele não se confunde. A iniciativa de criar essa organização veio justamente da percepção, inclusive das próprias autoridades dos EUA, de que o antigo modelo de governança do sistema internet - no qual de fato havia maior ingerência do governo (até mesmo pelo fato de historicamente as pesquisas sobre interconexão de computadores em redes terem sido financiadas pelos EUA) - deixara de ser satisfatório. O diagnóstico era o de que o sistema internet, pela dimensão que havia ganhado no curso do tempo, funcionaria melhor se gerido coletivamente, não respondendo diretamente a Estado algum.

Não foi por outra razão que os EUA decidiram se desvincular do sistema internet, deixando-o à regulação da Icann, como organização de cunho global - ente que, como o CGI.br, reflete o espírito livre da internet, na medida em que, também ele, é conduzido pelo consenso de vozes advindas dos mais diversos setores afetados pela internet no mundo (governos, setor privado, setor acadêmico, ONGs etc.). Como se viu, a Icann se pauta pelo chamado bottom-up, consensus-driven, multistakeholder model, configurando-se como organização de participação, voltada à elaboração de política pública transnacional.

Isso não quer dizer, claro, que a Icann seja território completamente neutro. Em se tratando de organização de participação, é natural que os atores que dela fazem parte procurem fazer valer suas perspectivas e visões, eventualmente conduzindo a política pública do sistema internet mais para um lado do que para outro. Mas a Icann procura ser organização de participação transparente e impessoal, buscando construir suas decisões pelo mais amplo consenso. O próprio Brasil, por integrar a comunidade da Icann, pode buscar influir nos rumos do sistema internet global pelas vias de participação lá existentes.

O interesse nacional dos países em geral - Brasil e EUA inclusos - só é atendido quando o sistema internet funciona; e o sistema só funciona bem quando é conduzido em prol da coletividade (e não em benefício apenas de Estados ou grupos específicos). O sistema internet é o tipo de utilidade que só atende integralmente à necessidade de entes individualizados (Estados, 
empresas etc.) na medida em que tenha razoavelmente em vista o interesse de todos.

Estar ou não vinculado à Icann não é opcional na hipótese de o Brasil decidir fazer parte da internet. O país de fato poderia, pois é soberano, optar pelo isolamento, criando, por exemplo, sua própria rede de interconexão de computadores, em âmbito apenas nacional. Ao tomar essa decisão, contudo, seria naturalmente excluído do fluxo de informações e de investimentos internacionais. Do ponto de vista prático, não há como o território brasileiro estar ao mesmo tempo conectado à internet (tal qual a conhecemos) e desvinculado da Icann, que é de fato a coordenadora global do sistema.

A hipótese de o atual modelo de governança do sistema internet no Brasil ser completamente estatizado, extinguindo-se o arranjo institucional plural e baseado em corregulação não estatal, composto por CGI.br e NIC.br, poderia ser considerada necessária a partir da ideia de que o interesse coletivo é melhor tutelado pelo Estado. ${ }^{41}$ Por essa perspectiva, a elevada importância da internet para a coletividade e para o país justificaria que o Estado, supostamente o porta-voz do interesse público e seu maior guardião, cuidasse, ele próprio e sozinho, de regulá-la, por meio de regulação pública.

Mas fazer o Estado presente ou onipresente pode não ser o melhor remédio. As soluções - baseadas ou não na figura estatal - devem ser formatadas à luz do contexto em que serão aplicadas. Nem sempre o interesse coletivo está melhor nas mãos do Estado. De modo que, se em tese o Brasil poderia sujeitar o sistema internet em território nacional à regulação puramente estatal, o fato é que a regulação no âmbito apenas nacional (estatal ou não estatal, tanto faz) tem espaço limitado para inovar. Não seria possível ao Estado, por exemplo, regular o sistema internet no Brasil em total contraposição à política global da Icann. O território brasileiro, enquanto parte de um todo, não poderia inverter a lógica das coisas; seu espaço de atuação obrigatoriamente seria conformado pelas diretrizes da política global do sistema internet.

Mesmo ao se levar em conta que normas produzidas pelo Estado em tese são dotadas de maior grau de coerção (enforcement), seria forçoso concluir que a regulação estatal, no caso do sistema internet, não poderia, para realmente conseguir induzir comportamentos, valer-se pura e simplesmente da sua força impositiva.

${ }^{41}$ Para uma crítica geral dessa premissa, SUNDFELD, Carlos Ari. Direito administrativo para céticos. 2. ed. São Paulo: Malheiros, 2014. p. 139-140. 
Regulação puramente impositiva (top-down) é adequada e desejável quando aplicada em ambientes relativamente restritos, pequenos, homogêneos. O sistema internet abarca toda a sociedade, em nível global; trata-se, pois, de setor altamente complexo, heterogêneo e difuso. Nesse tipo de ambiente, a regulação tenderá a ser mais eficiente e eficaz se for baseada no consenso e no reconhecimento das necessidades e preferências do seu público-alvo. ${ }^{42}$

Nem tudo o que é coletivamente relevante precisa ser regulado ou controlado direta ou exclusivamente pelo Estado. Há outros instrumentos à disposição - tais como a corregulação, que transcende o plano apenas estatal - que permitem ao Estado participar e influir decisivamente sobre espaços coletivos relevantes, sem, contudo, monopolizá-los.

A definição do atual modelo de governança do sistema internet no Brasil foi concluída após a edição, pelo CGI.br, da já aludida Resolução n⿳ํㅡㄹ 001/2005, de 14 de fevereiro de 2006. Esse texto formalizou a atribuição de o NIC.br executar o registro de nomes de domínio, alocar endereços IP e administrar o domínio de primeiro nível “.br” (art. 1ํ). Foi legítima a decisão do CGI.br de atribuir ao NIC.br exclusividade na operação do domínio ".br"?

A resolução editada pelo CGI.br é legal. Ao fazê-lo, o comitê não delegou - e nem poderia tê-lo feito - funções propriamente estatais, reservadas ao Estado brasileiro. Como visto, as atividades de registro de nomes de domínio sob o ".br" e a atribuição de números IP nunca estiveram inseridas no bojo de atividades exclusivas do Estado (e, portanto, sua delegação nunca foi objeto de reserva legal).

A resolução não promoveu delegação nova. A administração do ".br" desde o início ficou sob a responsabilidade de terceiros - antes a Fapesp, depois o NIC.br. O grupo técnico responsável pelo “.br" permaneceu sendo

42 Giandomenico Majone, ao comentar um tipo de regulação na qual a do sistema internet poderia ser enquadrada (regulation as "club goods"), afirma: "A implicação geral do modelo é que harmonização do tipo top-down é desejável apenas quando o mercado for relativamente pequeno e homogêneo. Em grandes mercados a harmonização tende a ser provocada não por políticas públicas impostas 'de cima para baixo', mas por meio do reconhecimento de necessidades e preferências em comum. O ponto principal é que regras são bens públicos no sentido de que cumprem funções tidas por desejáveis pela comunidade na qual são aplicáveis - mas isso não significa que elas precisem ser estabelecidas por diplomas normativos estatais. Uma boa regra sobre padrões técnicos, por exemplo, precisa refletir as necessidades, preferências e recursos da comunidade de usuários (e não a visão de alguém sobre o 'interesse público')" (tradução livre de excerto do artigo: The transformations of the regulatory state. Osservatorio sull'Ánalisi d'Impatto della Regolazione, 2010. p 18. Disponível em: <www. osservatorioair.it/wp-content/uploads/2010/10/Paper_Majone_RegulatoryState_sept2010. $\mathrm{pdf}>$ ). 
o mesmo. Houve mudanças no plano formal, mas não na prática da gestão do domínio ".br". A resolução veio apenas oficializar situação de fato já consolidada.

Não é correta a tese de que a gestão do domínio ".br" não poderia ter sido atribuída ao NIC.br, associação de direito privado, por supostamente representar o Brasil ou o Estado brasileiro na internet. Os ccTLDs, tais como o ".br" e o ".fr", por exemplo, não remetem diretamente a países - no caso, Brasil e França, respectivamente. Remetem, isto sim, a regiões geográficas, que por sua vez podem corresponder a países. Os "nomes" dos ccTLDs foram, por convenção, definidos com base na tabela ISO-3166, aludindo, desse modo, a códigos de países (e não aos próprios países). Tanto é assim que o processo de atribuição de ccTLDs passou ao largo da política; não envolveu relações diplomáticas entre Estados. As delegações de ccTLDs, como relatado, em geral derivaram de relações puramente acadêmicas entre pesquisadores alocados nos EUA e em diversas regiões do mundo.

Não faz sentido, pois, afirmar que o “.br" seja, ou deveria ser, uma espécie de "bem público" de titularidade estatal pelo simples fato de o "br" ser um código que remeta ao território correspondente ao Estado brasileiro, ou ao nome do país. Também por esse prisma não seria correto questionar a detença de exclusividade do ".br" por uma associação de direito privado (NIC.br).

\section{Conclusão}

Normalmente encaramos o novo de maneira instintiva e reativa, negando-o, rejeitando-o, criticando-o, talvez na expectativa (consciente ou inconsciente) de afastar as mudanças e, com elas, o custo de deixar o conforto. É natural que tudo que fuja à normalidade gere resistência. Mas ela não costuma persistir no tempo.

Quando Massimo Bottura - hoje um dos mais renomados chefes de cozinha e proprietário de um importante restaurante localizado na pequena cidade de Modena, na Itália, coroado com três estrelas do Guia Michelin serviu pela primeira vez seu prato mais conhecido, uma porção bastante reduzida de massa, ele chocou Modena. O gesto, que mudou uma receita clássica, que desde tempos imemoriais era repetida em praticamente todos os lares da Itália, foi interpretado como insulto à tradição e demonstração de inaptidão para cozinhar. 
Como explicar essa rejeição inicial a um futuro star? Os modenenses, quando iam ao seu estabelecimento, esperavam mais do mesmo, condicionados que estavam por padrões e convenções que dificultavam a compreensão da proposta inovadora. Por destoar da noção solidificada no imaginário (a massa da nonna!), rejeitavam-na e a rotulavam como equivocada.

Bem, o novo, o diferente pode de fato ser um desastre, mas para avaliálo é preciso o escrutínio de suas próprias características, com premissas e parâmetros adequados, levando a sério a proposta do cozinheiro, e não apenas o que ele intencionalmente quis rejeitar.

Talvez algumas das dúvidas internas quanto ao modelo brasileiro de regulação do sistema internet sejam fruto menos das próprias características deste do que de expectativas tradicionais formadas para outros contextos. Possivelmente o problema esteja menos no objeto e mais nas premissas, quando se afirma que a regulação brasileira do sistema internet, para atender ao interesse público, deveria, ajustando-se a nosso imaginário jurídico antigo, ser cuidada só pelo Estado.

O fato de questões importantes, que de algum modo remetam ao interesse da coletividade, normalmente serem organizadas por regulação estatal, por um viés estritamente nacional - quando muito, por meio de colaboração internacional entre Estados nacionais - , não parece ser suficiente para afastar a opção do Estado brasileiro quanto à governança do sistema internet. O Brasil não instituiu quanto a isso uma regulação puramente estatal, organizada por um viés estritamente nacional. Mas por que deveria tê-lo feito?

É verdade que o Estado brasileiro não monopoliza o modelo de gestão da internet, mas dele participa. Ele é baseado em corregulação, envolvendo atores variados, de diferentes setores (Estado, sociedade civil organizada, usuários do sistema internet, técnicos, acadêmicos etc.). $\mathrm{O}$ modelo, plural e permeável a diferentes vozes, foi imaginado para dar conta da riqueza e da pluralidade da internet.

O Estado entendeu que a corregulação seria, no caso do sistema internet, mais eficiente e mais ajustada às suas peculiaridades. Reconheceu, também, especificamente quanto a essa temática, suas próprias limitações, pois pouco poderia fazer se quisesse estatizar por completo a regulação de um empreendimento global e altamente ramificado, que depende de centralização organizacional em escala mundial para existir e operar.

Mas o modelo brasileiro de regulação do sistema internet não importou em mera aceitação da realidade. A partir dos fatos, incontestáveis (impossibilidade de o Estado regular em contraposição à Icann), foram criados 
instrumentos para que o Estado tivesse voz ativa; habilmente procurou-se equalizar a tensão entre o viés global e local da internet, permitindo a participação relevante do Estado (que preside e tem muitos assentos no CGI.br), ao mesmo tempo que se possibilitou a participação efetiva da sociedade civil (engenheiros, acadêmicos, técnicos, representantes de setores especialmente afetados pela internet etc.). O modelo, assim, abriu espaço para que o Estado exercesse seu papel, porém não lhe atribuiu o monopólio da regulação.

Esse tipo de regulação (corregulação) pode ser um dos indícios relevantes da existência do que alguns acadêmicos norte-americanos têm chamado de direito administrativo global. Ao se propor a equalizar interesses diversos por meio do consenso, por um modo que as organizações puramente estatais não têm sido capazes de fazer, o modelo revela potencial para ser replicado em outros setores e nichos da sociedade em que, como no caso do sistema internet, o objeto a ser tutelado pela regulação seja global, e não puramente nacional, nem puramente estatal ou privado.

\section{Referências}

CASINI, Lorenzo. Além do Estado: o surgimento da administração global. Revista de Direito Administrativo, Rio de Janeiro, v. 267, p. 13-39, set./dez. 2014. CHITI, Edoardo; MATTARELLA, Bernardo Giorgio(Org.). Global administrative law and EU administrative law: relationships, legal issues and comparison. Berlim: Springer, 2011.

FERNÁNDEZ-SHAW, Félix. Organización internacional de las telecomunicaciones y de la radiodifusión. Madri: Tecnos, 1978.

FREITAS, Andrey Vilas Boas; FREITAS, Igor Vilas Boas. Os novos mercados de nomes e números da internet - reestruturação do sistema de governança brasileiro. Núcleo de Estudos e Pesquisas/CONLEG/Senado, Brasília, 2013 texto para discussão no 139. Disponível em: <www.senado.leg.br/estudos>.

GONÇALVES, Pedro. Regulação administrativa da internet. Revista de Direito Público da Economia - RDPE, Belo Horizonte, ano 1, n. 1, p. 177-199, jan./mar. 2003. 
KINGSBURY, Benedict; KRISCH, Nico; STEWART, Richard B. The emergence of global administrative law. Disponível para consulta no sítio eletrônico do Global Administrative Law Project da New York University School of Law: $<$ www.iilj.org/gal/>.

LINDSAY, David, International domain name law - Icann and the UDRP. Portland: Hart Publishing, 2007.

MAJONE, Giandomenico. The transformations of the regulatory state. Osservatorio sull'Ánalisi d'Impatto della Regolazione. 2010. Disponível em: $<$ www.osservatorioair.it/wp-content/uploads/2010/10/Paper_Majone_ RegulatoryState_sept2010.pdf>.

NASSER, Salem H. O direito global em pedaços - regimes, fragmentação e pluralismo. V. 1 de texto apresentado à Escola de Direito de São Paulo da Fundação Getulio Vargas (FGV Direito SP) para fins de progressão na carreira de docente da instituição (2012).

NEVES, Kelli Priscila Angelini. Nomes de domínio e o sistema administrativo de conflitos de internet. Dissertação (mestrado) - Pontifícia Universidade Católica, São Paulo, 2013.

RAVENTÓS, Alberto. Servicios de valor añadido: conmutación de datos por paquetes, por circuitos... In: CREMADES, Javier (Coord.). Derecho de las telecomunicaciones. Madri: La Ley, 1997.

SUNDFELD, Carlos Ari. Direito administrativo para céticos. 2. ed. São Paulo: Malheiros, 2014.

SUNDFELD, Carlos Ari; ROSILHO, André. Direito e políticas públicas: dois mundos? In: ___ _ _ Direito da regulação e políticas públicas. São Paulo: Malheiros, 2014.

SUNDFELD, Carlos Ari. Regime do serviço de valor adicionado a telecomunicações. In: . Pareceres, v. I - Direito administrativo econômico. São Paulo: Thomson Reuters; Revista dos Tribunais, 2013.

TCHIKAYA, Blaise. Le droit international des télécommunications. Paris: PUF, 1998. 